\title{
Planejamento e participação: os eventos nacionais na área da educação após a Constituição de 1988
}

\author{
Planning and participation: national events in education after the 1988 Constitution
}

\author{
Planeación y participación: los eventos nacionales en el área de la \\ educación posterior a la Constitución de 1988
}

\author{
MARISA RIBEIRO TEIXEIRA DUARTE* \\ MARIA ROSIMARY SOARES DOS SANTOS**
}

\begin{abstract}
RESUMO - O artigo discute a participação de atores diversos no planejamento das políticas públicas em educação com foco nas sistemáticas de organização dos encontros, congressos e conferências que congregaram educadores, militantes políticos e entidades da área de educação, suas proposições e divergências no diagnóstico da educação brasileira e na formulação de planos nacionais de educação. O estudo investiga a Semana Nacional de Educação para Todos e a Conferência Nacional de Educação para Todos, realizadas em 1993 e 1994; o I e II Congressos Nacionais de Educação realizados em 1996 e 1997; e a Conferência Nacional de Educação de 2010. Além de mudanças nas concepções de planejamento estatal, considera-se que esses eventos contribuem para a disseminação de lógicas comuns de ação, permitindo a obtenção de consensos, e, para que atores responsáveis pela implementação de políticas educacionais, em territórios socialmente desiguais e diversos, persigam de forma ativa os resultados acordados desejáveis.

Palavras-chave - Planejamento. Plano Nacional de Educação. Participação social. Lógicas de ação. Entidades da educação.
\end{abstract}

\begin{abstract}
The article discusses the participation of different actors in the planning of public policies in education with a focus on systematic organization of meetings, congresses and conferences that brought together educators, political activists and authorities in the area of education, their propositions and differences in the diagnosis of Brazilian education and in the formulation of national education plans. The study investigates the National Week on Education for All and the National Conference on Education for All held in 1993 and 1994, the I and II National Conference on Education held in 1996 and 1997, and the National Education Conference 2010. In addition to changes in conceptions of state planning, it is considered that these events contribute to the spread of common logics of action, allowing for consensus building and so that actors responsible for the implementation of educational policies in territories socially unequal and diverse, pursue actively the results agreed desirable.
\end{abstract}

Keywords - Planning. National Education Plan. Social participation. Logics of action. Education entities.

RESUMEN - Este artículo discute la participación de los diversos actores en el planeamiento de las políticas públicas en educación con enfoque en sistemáticas de organización en los encuentros, congresos y conferencias que congregaron a educadores, militantes, políticos y entidades del área de la educación, a sus propuestas y divergencias en el diagnóstico de la educación brasilera y en la formulación de los planes nacionales de educación. El estudio investiga la "Semana Nacional de Educação para Todos"; la "Conferência Nacional de Educação para Todos, realizadas en 1993 y 1994; el I y II Congresos Nacional de Educación, realizados los años de 1996 y 1997; así como la Conferência Nacional de Educación efectuada el año 2010. Adicionalmente, las modificaciones en las concepciones de planeamiento estatal, consideradas eventos que contribuyen a la diseminación de lógicas comunes de acción que permiten la obtención de consensos o no en los cuales diferentes actores, responsables por la implementación de políticas educacionales en territorios socialmente desiguales y diversos persiguen de distintas formas determinados resultados deseables y acuerdos.

Palabras clave - Planeamiento. Plan Nacional de Educación. Participación social. Lógicas de acción. Entidades de la educación.

\footnotetext{
* Doutora em Educação pela Universidade Federal Fluminense (Rio de Janeiro, RJ, Brasil) e Professora na Universidade Federal de Minas Gerais (Belo Horizonte, MG, Brasil).E-mail:<mmduarte@ufmg.br>.

**Doutora em Educação pela Universidade Estadual Paulista Júlio de Mesquita Filho e Professora na Universidade Federal de Minas Gerais (Belo Horizonte, MG, Brasil).E-mail: <mrosi@ufmg.br>.
} 
A formulação dos planos nacionais de educação no Brasil foi historicamente acompanhada da realização de fóruns, conferências ou encontros que congregaram educadores, políticos, profissionais de educação e militantes com reivindicações as mais diversas na área. Este artigo analisa a Semana Nacional de Educação para Todos (SNET) e a Conferência Nacional de Educação para Todos (CNET), eventos realizados no processo de formulação e implementação do I Plano de Decenal da Educação para Todos em 1993 e 1994, respectivamente. Os I e II Congressos Nacionais de Educação (CONEDs), ${ }^{1}$ que precederam a elaboração do I Plano Nacional de Educação (Projeto de Lei 5.155/1998), realizados em Belo Horizonte em 1996 e 1997, e a I Conferência Nacional de Educação (CONAE), que antecedeu a apresentação do Projeto de Lei 8035/2010, atualmente em tramitação no Senado.

O estudo efetuou a análise da sistemática de organização desses eventos e do conteúdo do diagnóstico formulado sobre a educação brasileira à época. A pesquisa da sistemática de organização efetuou-se mediante o levantamento da composição da(s) comissão(ões) organizadora(s) e a do conteúdo da regulamentação orientadora de seu funcionamento e das entidades participantes. Para a análise da relação estabelecida entre o diagnóstico e o contexto do período, buscou-se estabelecer os argumentos que legitimaram a(s) prioridade(s) política(s) conferida(s) para a atuação da União no campo da educação básica e da educação superior. Ressalta-se que neste trabalho não foram analisadas as metas aprovadas nos planos estudados e sim o processo de planejamento.

A formulação de políticas públicas em educação é tradicionalmente analisada pelo viés dos interesses e atores que mais as influenciaram. Entretanto, Freitag (1986) já alertava sobre o papel da indústria cultural na disseminação de formações discursivas em torno das políticas educativas; a essas práticas discursivas contrapomos aquelas desenvolvidas no âmbito dos atores coletivos organizados. $\mathrm{Na}$ atualidade as discussões em torno do Sistema Educacional no Brasil contam com a expressiva coordenação do Ministério da Educação e de entidades que participaram das lutas sociais pela democratização do país e da educação. Nesse sentido, as Conferências Nacionais de Educação apresentam-se como situações de comunicação, onde se operam enunciações constitutivas de uma formação discursiva sobre o planejamento educacional. Este estudo considera que as conferências operam práticas discursivas, ou seja, operam formas discursivas de ação sobre o mundo, produzidas fundamentalmente nas relações de forças sociais (MAINGUENEAU, 2008).

\section{Planejamento educacional e ESPAÇOS DE PARTICIPAÇÃO}

As análises dos encontros, congressos e conferências que congregaram educadores, militantes políticos e entidades da área de educação, de suas proposições e divergências para formulação de planos nacionais de educação são ainda incipientes. O levantamento efetuado revelou, também, a existência de uma literatura mais expressiva relativa à formulação e avaliação do Plano Nacional de Educação 2001-2011, porém mais reduzida sobre o Plano Decenal de Educação para Todos (PDET). A este último foram atribuídos em diversos artigos (SILVA JR., 2002; FONSECA, 1998) juízos de valor que o associavam ao contexto neoliberal do período sem uma fundamentação mais expressiva da tradução efetuada pelos atores locais ou da função política de planejamento que esse cumpria. Para Silva Júnior (2002) o PDET constituiu no Brasil a primeira expressão orgânica do movimento reformista mundial, na esfera da educação e seria a expressão brasileira do movimento planetário orquestrado pela United Nations Educational, Scientific and Cultural Organization (Unesco) e pelo Banco Mundial (BM) como orientadores das políticas públicas para a educação, que resultaria na reforma educacional brasileira dos anos de 1990. Tal modus operandi seria típico de um hiperpresidencialismo e da lógica do novo paradigma político que se inaugurava no Brasil depois do processo de desgaste imposto aos canais políticos de mediação entre Estado e sociedade civil nos anos de 1980. Fonseca (1998) afirma que os documentos preliminares que fundamentaram o Plano Decenal foram enfáticos quanto à intenção de aderir imediatamente às orientações internacionais.

Entretanto, a literatura pesquisada (SILVA JR., 2002; FONSECA, 1998; MACHADO, 2000; GUEDES, 2003) revela, ainda, posições divergentes na caracterização e significado do Plano Decenal em relação aos processos anteriores de formulação do planejamento educacional. De um lado, afirmativas que apontam para a emergência de um modelo de planejamento participativo em sintonia com "os avanços democratizantes alcançados pela sociedade brasileira" (MACHADO, 2000, p. 42), de outro, a afirmação de que, mesmo com a divulgação de uma ampla participação e debate na elaboração do Plano, se privilegiou o "conteúdo do Plano elaborado pelo Grupo Executivo de tecnocratas do MEC" (GUEDES, 2003).

Já no governo Fernando Henrique Cardoso, procedimentos de planejamento estratégico centralizados no MEC foram retomados. Em dezembro de 1996, tem-se a aprovação da Emenda Constitucional no ${ }^{-14}$, da Lei de Diretrizes e Bases da Educação Nacional (LDBEN) e da Lei 9.424, que regulamentou o Fundo de 
Manutenção e Desenvolvimento do Ensino Fundamental (FUNDEF). Essas normas articularam os recursos estaduais e municipais provenientes das transferências constitucionais obrigatórias com a atribuição de competências aos entes federados para com a oferta das diferentes etapas da educação básica. ${ }^{2}$ No período desse governo, entidades não governamentais e os partidos de oposição organizaram congressos nacionais de educação e propuseram Plano Nacional de Educação (Projeto de Lei 4155 de 1998).

No intervalo de doze anos (1999-2012), o portal SciELO registra a publicação de 18 artigos relacionados ao descritor "Plano Nacional de Educação", sendo nove desses publicados em número temático do periódico Educação \& Sociedade (v. 31, n. 112, jul.-set. 2010). Nesse número, o editorial (2010) informa trazer reflexões sobre as questões mais importantes, relativas ao Plano Nacional da Educação (PNE 2011-2020), já identificadas na Conferência Nacional da Educação (CONAE). Dois dos artigos presentes na revista (DOURADO, 2010; AGUIAR, 2010) avaliam o PNE 2001-2011; os demais analisam temas específicos da área de políticas públicas em educação, tratados na CONAE em março desse mesmo ano.

Em relação ao tema deste estudo, destaca-se o artigo de Bollmann (2010) que identifica a importância da atuação das entidades constituintes do Fórum Nacional em Defesa da Escola Pública (FNDEP), denominadas pela autora como sociedade civil organizada. A autora destaca a importância das contribuições do Fórum e da realização dos Congressos Nacionais de Educação (CONEDs) em Belo Horizonte, para a elaboração do Projeto de Lei 4.155 (BRASIL, 1998), conhecido com projeto da sociedade de
Plano Nacional de Educação. ${ }^{3}$ Nesse artigo, Bollmann (2010) contrapõe, ainda, as duas estratégias políticas em disputa pelo planejamento da educação no país: uma voltada para ampliação da participação de entidades não governamentais e movimentos sociais de modo a intervir na formulação das diretrizes de planejamento educacional do país, e uma segunda estratégia voltada para o estabelecimento de mecanismos promotores de maior eficiência e eficácia na gestão sistêmica da educação.

Este estudo selecionou para análise da sistemática de planejamento os cinco eventos nacionais que resultaram na/da apresentação de proposições normativas para planos de educação e se autorreconhecem como instâncias ou modalidades de planejamento participativo e de gestão democrática da educação (Quadro 1).

A partir da segunda metade década de 1980, o termo planejamento participativo disseminou-se com conotações as mais diversas, ultrapassando as esferas do Ministério, das secretarias estaduais e municipais de educação e envolvendo de modo desigual outros atores privados, sindicatos e a mobilização midiática pela educação. Novos sujeitos passam a vocalizar proposições de mudanças/reformas na gestão educacional, especialmente as chamadas genericamente Organizações Não Governamentais (ONGs). Esses novos atores produziram, pelos questionamentos trazidos, rupturas com as concepções autoritárias de planejamento, desagregando o planejamento tecnocrático mais usual no país e incorporaram novas intermediações entre Estado e sociedade (HORTA, 1997). Sob esse termo genérico de chamada à participação encontravam-se opções de políticas as mais diversas, desde aquelas de matriz neoliberal, que propugnavam pela defesa da autonomia

Quadro 1 - Eventos nacionais associados à formulação de planos educacionais de abrangência nacional, posteriores à Constituição de 1988

\begin{tabular}{|c|c|c|c|c|c|c|c|}
\hline Evento & Data & Cidade & Local & Regulamento & $\begin{array}{c}\text { № estimado de } \\
\text { participantes }\end{array}$ & $\begin{array}{c}\text { № de entidades } \\
\text { organizadoras }\end{array}$ & $\begin{array}{l}\text { № de entidades } \\
\text { responsáveis } \\
\text { pela redação do } \\
\text { documento final }\end{array}$ \\
\hline SNET & $\begin{array}{c}10 / 5 \mathrm{a} \\
14 / 5 / 1993\end{array}$ & Brasília & & $\begin{array}{c}\text { Portaria MEC } \\
\text { n⿳ } 498 / 1993\end{array}$ & & MEC & 4 \\
\hline CNET & $\begin{array}{c}29 / 8 \text { a } \\
2 / 9 / 1994\end{array}$ & Brasília & $\begin{array}{c}\text { Academia } \\
\text { de Tênis }\end{array}$ & & \pm 1.600 & MEC & \\
\hline I CONED & $\begin{array}{c}31 / 7 \mathrm{a} \\
3 / 8 / 1996\end{array}$ & $\begin{array}{c}\text { Belo } \\
\text { Horizonte }\end{array}$ & UFMG & & \pm 5.000 & 12 & 13 \\
\hline II CONED & $\begin{array}{c}6 / 11 \mathrm{a} \\
9 / 11 / 1997\end{array}$ & $\begin{array}{c}\text { Belo } \\
\text { Horizonte }\end{array}$ & UFMG & & \pm 4.000 & 12 & 9 \\
\hline I CONAE & $\begin{array}{c}28 / 3 \mathrm{a} \\
1 / 4 / 2010\end{array}$ & Brasília & & $\begin{array}{c}\text { Portaria } \\
\text { Ministerial } \\
\mathrm{n}^{\mathrm{o}} \text { 10/2008 }\end{array}$ & $\begin{array}{c} \pm 3.500 \\
\text { (previsão) }\end{array}$ & 28 & \\
\hline
\end{tabular}

Fonte: elaboração das autoras. 
das unidades escolares como contrapartida aos ganhos de eficiência e eficácia, às primeiras reivindicações pela criação de novos espaços institucionais de deliberação como os fóruns mundiais e nacionais de educação.

\section{SEMANA NACIONAL DE EDUCAÇÃO, COMPROMISSO DE TODOS PELA EDUCAÇÃO E O PLANO DECENAL DE EDUCAÇÃO PARA TODOS}

Em março de 1990, o Brasil participou da Conferência Mundial de Educação para Todos (WCEFA), em Jomtien, na Tailândia, convocada pela Organização das Nações Unidas para a Educação, a Ciência e a Cultura (Unesco); pelo Fundo das Nações Unidas para a Infância (Unicef); pelo Programa das Nações Unidas para o Desenvolvimento (PNUD); e pelo Banco Mundial (BM). Dessa conferência resultaram posições consensuais dos signatários, sintetizadas na Declaração Mundial de Educação para Todos, tais como: "universalizar o acesso à educação e promover a equidade; concentrar a atenção na aprendizagem; ampliar os meios e o raio de ação da educação básica; propiciar um ambiente adequado à aprendizagem; e fortalecer alianças" (WCEFA, 1990). As proposições acordadas deveriam servir de base para as políticas educativas, especialmente dos países mais populosos do mundo, que lograram assiná-la. Ao Brasil, como integrante desse grupo, caberia "colaborar para os esforços mundiais na luta pela universalização da educação básica" (GARCIA, 1993, p. 99).

A preparação da delegação brasileira para a Conferência de Jomtien ocorreu no final do governo José Sarney (1985-1990). O país esteve representado na Reunião Preparatória para Jomtien realizada, no final de 1989, em Quito, no Equador, com a participação dos demais países da América Latina e do Caribe. Nesse fórum, a delegação brasileira propôs que os países, economicamente desequilibrados pela dívida externa deveriam ter parte do serviço da dívida revertida para seus próprios programas de alfabetização e educação básica. Esta iniciativa obteve apoio do Fundo das Nações Unidas para a Infância (UNICEF) e de outras agências multilaterais, mas os representantes do Banco Mundial mitigaram de modo acentuado a proposta, que aparece no documento final bastante esmaecida (GADOTTI, 2000). Essa é uma das propostas que não obtiveram consenso em Jomtien, na Tailândia.

Com a mudança de governo ocorrida em 1990 (governo Collor de Melo, 1990-1992), aqueles que prepararam as propostas que seriam levadas a Jomtien não compuseram a delegação brasileira que compareceu à Tailândia. Com exceção das pessoas vinculadas à sociedade civil, a delegação brasileira "não estava a par de todas as discussões anteriores, resultado da descontinuidade que sempre acontece quando há mudança de governo" (GADOTTI, 2000). Além disso, durante o breve mandato de Fernando Collor de Mello se observou um "congelamento" do debate sobre a Educação para Todos. Apenas um programa de abrangência nacional foi encaminhado pelo Ministério da Educação no período, o Programa Nacional de Alfabetização e Cidadania. Esse programa ressurgiu em 1993, quando o Ministério da Educação (MEC) foi convidado a participar da Conferência Mundial de Educação de Nova Delhi, a Education For All-9 - EFA-9 (GADOTTI, 2000, p. 27). Devido às mudanças de governo, a recepção no país das proposições formuladas em Jomtien adquiriu maior fôlego a partir do período governamental de 1992-1994 (governo Itamar Franco).

Para Machado (2000), a preparação para a participação na EFA-9 foi o elemento decisivo para desencadear o processo de elaboração do Plano Decenal de Educação para Todos (1993-2003). Em março de 1993, o MEC editou a Portaria 498 (BRASIL/MEC, 1993b), instituindo uma Comissão Especial, sob a coordenação da Secretaria de Ensino Fundamental, que teria um prazo de 60 dias para elaborar o PDET. Na execução dos trabalhos, a Comissão contaria com a participação de um Grupo Executivo composto por representantes do MEC, do Instituto Nacional de Estudos e Pesquisas Educacionais (INEP), da Coordenação Geral de Planejamento Setorial do MEC, do Conselho Nacional dos Secretários Estaduais de Educação (CONSED) e por representantes da União Nacional dos Dirigentes Municipais de Educação (UNDIME). Posteriormente, foi criado um Comitê Apoio (MEC, 1993), integrado por representantes de entidades governamentais, entidades não governamentais e pela Confederação dos Trabalhadores em Educação (CNTE), que passou a se chamar Comitê Consultivo do Plano Decenal de Educação para Todos (MACHADO, 2000, p. 39-40). A Portaria MEC no 498/1993 (BRASIL/MEC, 1993b) previa, ainda, a realização, no mês de maio daquele ano, da Semana Nacional de Educação para Todos com a finalidade debater a versão preliminar do Plano.

A documentação relacionada à Semana é esparsa e estrutura-se fundamentalmente a partir de fontes secundárias. Atas de reuniões e anais não foram localizados por esta pesquisa. A Semana de Educação para Todos, realizada em maio de 1993, consistiu em evento organizado pela equipe técnica do Ministério da Educação com o objetivo de aperfeiçoamento do documento a ser apresentado em Nova Delhi no final do mesmo ano (CUNHA, 1993; BRASIL/MEC, 1993b). A participação de especialistas convidados e de representantes ligados a entidades da área educacional pode ser caracterizada com base em dois critérios: pesquisadores e entidades ligadas 
à pesquisa educacional, como o Instituto Paulo Freire e o Centro de Estudos e Pesquisas em Educação, Cultura e Ação Comunitária e órgãos relacionados à gestão e regulamentação da educação, como o Conselho Federal de Educação, o Conselho Nacional de Secretários da Educação, a União dos Dirigentes Municipais de Educação. Destaca-se, ainda, a participação de representantes da Confederação Nacional dos Trabalhadores em Educação, ${ }^{4}$ entidade representativa dos sindicatos de trabalhadores em educação.

No âmbito da Comissão Executiva encarregada de sistematizar o PDTE, definiram-se três aspectos fundamentais para sua construção. O Plano deveria ser indicativo, ou seja, conter as diretrizes da política educacional passíveis de adequação às realidades dos Estados, municípios e escolas; constituído a partir de uma aliança de fundamento federativo com vistas à concretização do regime de colaboração; fundamentado na parceria com a sociedade civil, através da participação e contribuição dos segmentos organizados da sociedade e dos setores engajados na luta pela educação (MACHADO, 2000, p. 43-44).

A partir dessas definições preliminares, o processo de elaboração do Plano desenvolveu-se, basicamente, em três etapas: a primeira, equivalendo aos primeiros 60 dias de trabalho da Comissão Executiva e culminando na realização da Semana Nacional de Educação para Todos, quando foi firmado o Compromisso Nacional de Educação para Todos. A segunda etapa decorreria do debate deflagrado no âmbito dos estados e municípios, dos poderes Legislativo e Judiciário, nas entidades representativas e nas universidades em torno da primeira versão do Plano. Esta etapa culminou na elaboração da versão final do PDET, levada ao encontro da EFA-9 em Nova Delhi e orientaria a construção de planos decenais nos estados e municípios brasileiros. Por fim, uma terceira etapa envolveria debates nas escolas (GARCIA, 1993, p. 100-102).

A Semana Nacional de Educação para Todos resultou na assinatura do Compromisso Nacional de Educação para Todos, apresentado como "uma agenda de compromissos para orientar o Plano Decenal de Educação para Todos" (MEC, 1993, p. 83). Assinado pelo Ministro da Educação e por representantes dos poderes públicos e diversas entidades participantes da Semana (MEC, 1993, p. 83-89), o documento tornou-se referência para elaboração do Plano Decenal, cuja primeira versão foi concluída em junho de 1993 e apresentada como a proposta do governo para discussão junto à sociedade (GARCIA, 1993; MACHADO, 2000). Em seguida, foram constituídas "comissões tripartites", no âmbito dos estados subnacionais, coordenadas por secretários de educação, representantes da UNDIME e por delegados do MEC, com a tarefa de recolher e sistematizar contribuições ao
Plano Decenal. Posteriormente, realizou-se seminário com secretários e representantes de municípios de médio porte, com o intuito de debater o documento e para que esses municípios pudessem ajudar na divulgação e mobilização dos municípios pequenos. Além disso, a proposta foi enviada a diversas entidades não governamentais, aos parlamentares federais, estaduais e câmaras municipais, sendo também debatida em diferentes eventos promovidos por entidades da educação (MACHADO, 2000).

A terceira etapa de discussão do PDET consistiu no envio de exemplares do Plano, juntamente com uma sugestão de roteiro de discussão, a 45.000 escolas em todo o país. A discussão nas escolas tinha por objetivo não apenas apontar críticas e sugestões para o aprimoramento do Plano, mas também envolver os professores e dirigentes na sua implementação a partir da elaboração de projetos pedagógicos para as escolas tendo como referência as proposições do Plano (CUNHA, 1993, p. 29). Os debates realizados nas escolas visaram levantar subsídios ao Plano e constar como uma das etapas preparatórias para a Conferência Nacional de Educação para Todos (CNET), que deveria ocorrer no ano seguinte.

A CNET foi realizada em Brasília, no período de 29 de agosto a 2 de setembro de 1994, conforme consta em seus anais (MEC 1994, p. 18), e tinha como objetivos: "discutir estratégias de implementação e sustentação do Plano Decenal de Educação para Todos na União, nos estados e nos municípios; conhecer e discutir as experiências da política de educação para todos dos países do EFA9; propor estratégias e mecanismos de aperfeiçoamento da política de educação para todos nas instâncias de sua formulação e execução". O evento foi estruturado para em um primeiro momento apresentar e discutir os relatórios estaduais e os dos simpósios e seminários temáticos, culminando com a organização de painéis sobre os seguintes temas: a) os partidos políticos e o Plano Decenal; b) a integração estado-município; c) a questão do financiamento da educação básica; d) as estratégias e mecanismos de sustentação e continuidade da política de educação para todos. No segundo momento ocorreu a apresentação e discussão das diversas experiências dos países do EFA-9, com a participação dos organismos internacionais. Também seriam apresentadas, durante a Conferência, experiências inovadoras de educação básica, sobretudo as de educação especial, desenvolvidas no país (BRASIL/MEC, 1994, p. 19).

Participaram da CNET mais de 1.600 pessoas entre dirigentes e técnicos do MEC e dos sistemas estaduais e municipais de ensino; representantes da UNDIME e do CONSED nos estados, de organizações não governamentais, dos poderes Legislativo e Judiciário; reitores e dirigentes universitários; sindicatos, professores e entidades vinculadas à educação; além das delegações 
dos países do EFA-9 e representantes dos organismos internacionais. Os trabalhos foram concluídos com a assinatura do Acordo Nacional de Educação para Todos, com o qual se buscava avançar na implementação do PDET, definindo programas emergenciais em três dimensões consideradas estratégicas: as necessidades básicas de aprendizagem, a profissionalização do magistério e o regime de colaboração.

É em relação ao tema da "Valorização dos professores da educação básica" que a CNET faz divulgar, no âmbito do "Acordo Nacional de Educação para Todos", a importância da implantação de um piso salarial nacional do magistério, de um novo regime de trabalho (de 40 horas semanais com pelo menos $25 \%$ do tempo destinado a trabalho extraclasse) e planos de carreira. No documento do Acordo consta o Pacto pela Valorização do Magistério e Qualidade da Educação (BRASIL/MEC, 1994), onde e pela primeira vez estabeleceu-se orientação nacional quanto a um piso salarial profissional nacional do magistério (VIEIRA, 1998). A influência da CNTE se fez sentir nesse aspecto e com resistências das entidades ligadas aos governos subnacionais.

A relevância desse dispositivo constante no Acordo envolveu a inédita tentativa de regulamentação das políticas de profissionalização do magistério dos demais entes federados, pois o texto constitucional de 1988, ao assegurar autonomia político-administrativa aos entes federados, vedaria normas nacionais relacionadas com as relações de trabalho a serem adotadas pelos entes subnacionais da federação. Em contraponto, tanto o PDTE quanto os anais da Conferência de 1994 registram as preocupações e medidas de combate em relação ao desequilíbrio fiscal da federação, a municipalização de encargos sociais e educacionais, a ausência de investimentos federais na área, temas esses caros aos gestores representantes dos demais entes subnacionais. O conteúdo do PDTE tensiona entre demandas por mais recursos e valorização dos profissionais/trabalhadores em educação e a externalização das prioridades definidas em Jontiem, a serem reafirmadas naquele mesmo ano em Dakar.

Neste sentido, Garcia (1993, p. 102) assinala que o PDTE buscava sinalizar onde se deveriam concentrar esforços e recursos e quais as estratégias para universalizar o ensino fundamental e eliminar o analfabetismo, pretendendo com isso combater o "imediatismo dos programas e ações descoordenadas e isoladas. Entretanto, a participação da CNTE expôs a segunda formação discursiva presente no período, diferenciada das diretrizes de Jontiem e das demandas formuladas por gestores educacionais, ao priorizar medidas e mudanças relacionadas à profissionalização e condições de trabalho a que se achavam submetidos os(as) trabalhadores(as) de educação básica no setor público por todo o país.
O processo de elaboração do Plano Decenal de Educação para Todos representou, segundo Machado (2000, p. 51), "um novo patamar no conteúdo e na forma de estruturação das políticas educacionais, ensejando a articulação e a construção de consensos em torno das bases para a reforma educativa nacional". O valor de suas proposições e estratégias estaria, segundo a autora, na mobilização e na corresponsabilidade social empreendidas na construção do Plano. A nosso ver, a sistemática de elaboração do Plano Decenal de Educação é a primeira tentativa de âmbito federal, no período constitucional inaugurado em 1988, direcionada para a articulação de ações e prioridades entre os entes governamentais. $\mathrm{O}$ tema do regime de colaboração foi introduzido na Semana de Educação para Todos, nos encontros e documentos preparatórios da Conferência Nacional de Educação para Todos realizada em 1994. A participação mais expressiva de representantes da UNDIME e do CONSED expressou a alteração inicial com as concepções tecnocráticas de planejamento do período ditatorial, embora a sistematização do PDET permanecesse sob a coordenação da burocracia do Ministério do Planejamento.

Embora tenha sido interpretado na literatura nacional como um plano que submeteu a política educacional brasileira às diretrizes das agências internacionais, em especial do Banco Mundial, o documento do PDTE já continha alguns dos enunciados que iriam demarcar manifestações posteriores de entidades e atores que compunham o Fórum em Defesa da Escola Pública. Se a prioridade achava-se posta na externalização do consentimento com as prioridades estabelecidas em Jomtiem, a participação de outros atores nos debates que levaram à formulação do documento traz à cena temas caros aos períodos posteriores, como o regime de colaboração e o piso salarial nacional.

Por sua vez, a ausência de estudos que destaquem medidas e ações efetivas adotadas em decorrência do PDTE é sugestiva de uma reduzida eficácia operacional. O PDTE contribuiu muito mais para a externalização das diretrizes políticas nacionais em consonância com aquelas contidas na agenda internacional de educação e o conjunto de acontecimentos associadas a sua formulação e divulgação e funcionaram, por sua vez, como quadro de referência para a legitimação das decisões a serem adotadas no período governamental posterior.

\section{E II CONGRESSOS NACIONAIS DE EDUCAÇÃO E O PROJETO DE LEI DA "SOCIEDADE BRASILEIRA"}

A Constituição Federal aprovada em 1988 (art. 214) previa a elaboração de lei contendo Plano Nacional de Educação, de duração plurianual. Educadores e diversas 
entidades da área educacional já organizadas no Fórum Nacional em Defesa da Escola Pública ${ }^{5}$ (FNDEP) iniciaram, logo após a aprovação da Lei de Diretrizes e Bases da Educação (9.394/1996), discussões para a elaboração de Plano Nacional de Educação. A primeira reunião do FNDEP para esse fim ocorreu em janeiro de 1996, na Universidade de São Paulo, quando se decidiu pela organização do I Congresso Nacional de Educação, na tentativa de "reeditar com outros atores e outros objetivos, em outra conjuntura, a participação dos movimentos da sociedade brasileira na política de educação" (BOLLMANN, 2010, p. 665). Em 24 de abril de 1996 foi lançado o Manifesto à Sociedade Brasileira - Educação, Democracia e Qualidade Social. Neste manifesto, as entidades do FNDEP conclamavam a sociedade brasileira a "intervir na política educacional, definindo elementos para elaboração democrática de um Plano Nacional de Educação" e convocavam o I Congresso Nacional de Educação (I CONED, 1997).

No Manifesto declara-se que a sociedade brasileira, apesar da "retórica governamental", encontrava-se excluída de participar dos rumos da educação, devido à inexistência de "mecanismos efetivos de participação democrática". Também criticava-se a política educacional do período, vista como excludente e incapaz de resolver os problemas de jovens e adultos analfabetos; o baixo investimento financeiro na educação; o sucateamento das escolas e das universidades públicas e a baixa qualidade da educação [...] (I CONED, 1997). Por essas razões, seria necessário, conforme consta no Manifesto

[...] nossa intervenção para a construção de alternativas comprometidas com o fim da exclusão social, com a democracia e com a qualidade da educação brasileira. [...] visando à construção de um projeto políticopedagógico para a educação brasileira, pautando pela ética e pela participação democrática (I CONED, 1997).

Entre os dias 31 de julho a 3 de agosto de 1996, foi realizado, em Belo Horizonte, com o intuito de constituir-se em "um espaço e momento de debate aberto de propostas que viessem subsidiar a elaboração de um Plano Nacional de Educação" o I Congresso Nacional de Educação. A concepção política e metodológica do Congresso foi definida por uma comissão organizadora (Quadro 2), a partir dos aportes das entidades que compunham o FNDEP. A primeira achava-se expressa na escolha do tema central do Congresso - Educação, Democracia e Qualidade Social - como contraponto à política educacional oficial já caracterizada no Manifesto. A independência na definição de prioridades e a autonomia no financiamento do evento eram consideradas condições necessárias para "um evento planejado para questionar ações governamentais" (I CONED, 1997, p. 11).
Quadro 2 - Composição da comissão organizadora do I CONED

\begin{tabular}{|c|c|}
\hline Entidades & Representantes \\
\hline $\begin{array}{l}\text { AELAC - Associação de } \\
\text { Educadores da América Latina } \\
\text { e do Caribe }\end{array}$ & Maria Regina V. Pannuti \\
\hline $\begin{array}{l}\text { ANDE - Associação Nacional } \\
\text { de Educação }\end{array}$ & $\begin{array}{l}\text { Afrânio Mendes Catani, } \\
\text { César Augusto Minto, } \\
\text { Rubens Barbosa de Camargos }\end{array}$ \\
\hline $\begin{array}{l}\text { ANDES-SN Sindicato } \\
\text { Nacional dos Docentes das } \\
\text { Instituições de Ensino Superior }\end{array}$ & $\begin{array}{l}\text { Evandro Ferreira Passos, } \\
\text { Géria Maria Montanaro Franco, } \\
\text { Maria da Graça N. Bollmann, } \\
\text { Mauro Augusto B. Del Pino }\end{array}$ \\
\hline $\begin{array}{l}\text { ANFOPE - Associação } \\
\text { Nacional pela Formação dos } \\
\text { Profissionais da Educação }\end{array}$ & Aída Maria Monteiro \\
\hline $\begin{array}{l}\text { CNTE - Confederação } \\
\text { Nacional dos Trabalhadores } \\
\text { em Educação }\end{array}$ & $\begin{array}{l}\text { Arthur Rangel, } \\
\text { Delmar Steffen, } \\
\text { Juçara Dutra Vieira, } \\
\text { Júlio César Soares da Silva, } \\
\text { Wilmar Carvalho }\end{array}$ \\
\hline $\begin{array}{l}\text { CONTEE - Confederação } \\
\text { Nacional dos Trabalhadores } \\
\text { em Estabelecimentos de } \\
\text { Ensino }\end{array}$ & Edson de Paula Lima \\
\hline $\begin{array}{l}\text { DNTE-CUT - Departamento } \\
\text { Nacional dos Trabalhadores da } \\
\text { Educação - Central Única dos } \\
\text { Trabalhadores }\end{array}$ & José Luiz Pio Romera \\
\hline $\begin{array}{l}\text { FASUBRA - Federação de } \\
\text { Sindicatos de Trabalhadores } \\
\text { das Universidades Brasileiras }\end{array}$ & $\begin{array}{l}\text { João Eduardo do Nascimento, } \\
\text { Maria da Graça Ferro Freire }\end{array}$ \\
\hline $\begin{array}{l}\text { SINASEFE - Sindicato } \\
\text { Nacional dos Servidores } \\
\text { da Educação Federal de } 1^{\circ} \text {, } \\
2^{\underline{o}}, 3^{\circ} \text { Graus da Educação } \\
\text { Tecnológica }\end{array}$ & $\begin{array}{l}\text { Gilberto A. Almeida, } \\
\text { José Xavier S. Filho }\end{array}$ \\
\hline $\begin{array}{l}\text { UBES - União Brasileira dos } \\
\text { Estudantes Secundaristas }\end{array}$ & Júlio Salas \\
\hline $\begin{array}{l}\text { UNDIME - União Nacional } \\
\text { dos Dirigentes Municipais de } \\
\text { Educação }\end{array}$ & $\begin{array}{l}\text { Lisete Regina Gomes Arelaro, } \\
\text { Paulo Lousano }\end{array}$ \\
\hline $\begin{array}{l}\text { UNE - União Nacional dos } \\
\text { Estudantes }\end{array}$ & $\begin{array}{l}\text { Júlio Jader Costa, } \\
\text { Robson de Moraes }\end{array}$ \\
\hline
\end{tabular}

Fonte: I CONED, 1996, páginas pré-textuais.

Quanto aos procedimentos de organização, a comissão optou por desdobrar o tema central em cinco linhas temáticas: Estado e educação; sociedade civil e educação; trabalho e educação; educação básica e educação superior. Essas linhas foram subdivididas em dezoito subtemas, cujo desenvolvimento ocorreu mediante conferências, mesas-redondas e apresentação de trabalhos. Na plenária de encerramento, as discussões e contribuições provenientes dos grupos temáticos foram sistematizadas e relatadas pela comissão organizadora, resultando, ao final, no documento Educação, Democracia e Qualidade Social - Carta de Belo Horizonte, que apresentava 
as diretrizes e estratégias para a elaboração do PNE (I CONED, 1997, p. 12-13). Esse documento serviu de base para a continuidade do processo de construção do Plano e preparação do II CONED, concebido como momento de discussão e aprovação do PNE - Proposta da Sociedade Brasileira.

Em agosto de 1997, as entidades componentes do FNDEP apresentaram o documento Subsídios às Discussões Preparatórias do II CONED para apoiar os debates sobre o PNE nas diferentes instâncias organizativas e nos diferentes eventos programados em todo o território nacional (congressos, seminários, encontros, debates, etc.) que antecederiam à realização do Congresso, também em Belo Horizonte, no período de 6 a 9 de novembro daquele ano. Coube à Comissão Organizadora do II CONED acompanhar esses debates e sistematizar as contribuições para apreciação da plenária. A composição da comissão responsável pela primeira redação do projeto de PNE da sociedade manteve quase as mesmas pessoas e entidades responsáveis pela sistematização do documento de 1996 (Quadro 3). Com esses procedimentos pretendeu-se que "tal Plano [extrapolasse] o caráter de mero documento formal para transformar-se num referencial político de atuação da sociedade" (II CONED, 1997, p. 57).

Quadro 3 - Composição da comissão responsável pela sistematização do PNE, formulado no II CONED

\begin{tabular}{|l|l|}
\hline \multicolumn{1}{|c|}{ Entidades } & \multicolumn{1}{c|}{ Representantes } \\
\hline $\begin{array}{l}\text { AELAC - Associação de } \\
\text { Educadores da América } \\
\text { Latina e do Caribe }\end{array}$ & Maria Regina V. Pannuti \\
\hline $\begin{array}{l}\text { ANDE - Associação Nacional } \\
\text { de Educação }\end{array}$ & $\begin{array}{l}\text { César Augusto Minto, } \\
\text { Nobuko Kawashita }\end{array}$ \\
\hline $\begin{array}{l}\text { ANDES-SN Sindicato } \\
\text { Nacional dos Docentes } \\
\text { das Instituições de Ensino } \\
\text { Superior }\end{array}$ & $\begin{array}{l}\text { Géria Maria Montanaro } \\
\text { Franco, } \\
\text { Maria da Graça N. Bollmann }\end{array}$ \\
\hline $\begin{array}{l}\text { CNTE - Confederação } \\
\text { Nacional dos Trabalhadores } \\
\text { em Educação }\end{array}$ & $\begin{array}{l}\text { Juçara Dutra, Márcia Dorneles, } \\
\text { Maria Teresa Leitão }\end{array}$ \\
\hline $\begin{array}{l}\text { ADUSP } \\
\text { Aosé Marcelino Resende Pinto, }\end{array}$ \\
\hline $\begin{array}{l}\text { DNTE-CUT - Departamento } \\
\text { da Educação - Central Única } \\
\text { dos Trabalhadores }\end{array}$ & $\begin{array}{l}\text { José Luiz Pio Romera } \\
\text { Otaviano Heleno }\end{array}$ \\
\hline $\begin{array}{l}\text { FASUBRA - Federação de } \\
\text { Sindicatos de Trabalhadores } \\
\text { das Universidades Brasileiras }\end{array}$ & Maria da Graça Ferro Freire \\
\hline $\begin{array}{l}\text { ADFSCAR } \\
\text { SMED - Diadema }\end{array}$ & $\begin{array}{l}\text { Marília Leite Washington, } \\
\text { Rubens Barbosa de Camargo }\end{array}$ \\
\hline Lívia Castro \\
\hline
\end{tabular}

Fonte: II CONED. Plano Nacional de Educação: proposta da sociedade brasileira. 1997a.
Tanto os procedimentos de formulação quanto os de implementação do Plano elaborado em 1993 e os do Plano elaborado no II CONED previam a realização de eventos diversos de disseminação de diagnósticos e propostas entre atores com atividades de âmbito subnacional na área da educação. Para seus organizadores, o II CONED constituiu um esforço coletivo de construção de Plano Nacional de Educação, viabilizado por intermédio das discussões das mesas-redondas, conferências, apresentação de trabalhos e comunicações e, principalmente, das plenárias temáticas e na plenária final (II CONED, 1997a, p. IX).

A proposta de Plano aprovada no II CONED consubstanciou-se no Projeto de Lei 5.155/1998, enviado ao Congresso Nacional no dia 10 de fevereiro pelo deputado federal Ivan Valente e subscrito por mais de 70 deputados e todos os líderes dos partidos de oposição da Câmara dos Deputados. Segundo Valente e Romano (2002, p. 98), o PNE da Sociedade Brasileira reivindicava o fortalecimento da escola pública estatal e a plena democratização da gestão educacional como eixo do esforço para universalizar a educação básica. Para tanto, propunha a ampliar o gasto com a educação para 10\% do Produto Interno Bruto (PIB), organizar a gestão educacional e tornar efetivo o Sistema Nacional de Educação. O PNE indicava, a partir de um "diagnóstico de possibilidades e limitações [da educação], construído com base na realidade nacional e através de comparações com [...] diferentes países", propostas para a Organização da Educação Nacional, com diretrizes e metas para consolidar o sistema nacional de educação, a gestão democrática e o financiamento da educação. Partia, segundo Bordignon (2011), da organização da educação como um todo para, na sequência, detalhar as diretrizes e metas dos diferentes níveis e modalidades da educação, as diretrizes e metas relativas à formação e valorização dos profissionais da educação, do magistério e das áreas técnicas e administrativas, nos diversos níveis e modalidades da educação brasileira (II CONED, 1997a, páginas pré-textuais).

A construção do projeto de PNE - Proposta da Sociedade Brasileira - tinha entre seus enunciados legitimadores a ideia de planejamento e gestão pública "democrático-participativa", termo esse emergente no início dos anos de 1990, nos programas de governo do partido de oposição ao governo Fernando Henrique Cardoso (1995-2002), o Partido dos Trabalhadores. Tratava-se, pois, de disputar, no âmbito da sociedade e do Poder Legislativo, projetos e concepções políticas de educação. A literatura de política educacional, entretanto, vai contrapor as duas proposições de PNE, identificandoas, não como projetos partidários diferenciados e em disputa, mas como concepções diversas de planejamento da articulação entre Estado e sociedade no campo educacional. 
Nesse sentido, afirma Bordignon (2011, p. 23) em relação ao Plano de Educação - Proposta do Executivo ao Congresso Nacional (Projeto de Lei 4.173/1998) -, que este foi elaborado no âmbito INEP/MEC com o apoio de entidades como o CONSED e a UNDIME, era de caráter técnico e com objetivos e metas segmentados por temas, sem a visão de totalidade da educação. Freitas (2007) por sua vez, considera que a aprovação da Lei 10.271/2001 - que instituiu o Plano Nacional de Educação - se fez em prejuízo da proposta apresentada no contexto do I e II CONEDs. Estas, ainda segundo Freitas (2007), defendiam a instituição do Sistema Nacional de Educação e entendiam a gestão democrática como um processo estratégico de superação do autoritarismo, do individualismo, de desigualdades socioeconômicas e propiciador do trabalho coletivo participativo na construção de uma sociedade fundada na justiça social. Bollmann (2010), uma das redatoras do PNE elaborado no II CONED, considera que a proposta da sociedade brasileira enfatizou a construção coletiva e democrática, com base na reflexão acumulada nos movimentos sociais do campo da educação, e expressa as concepções das entidades do campo democrático-popular que integravam o FNDEP.

A formação discursiva orientadora da ação, entre aqueles que participaram da elaboração do Plano Nacional de Educação no I e II CONED, enuncia a autonomia entre o que proposto pela sociedade em oposição à ação governamental do período. Ao ressaltar essa dicotomia, as práticas discursivas deslocavam a disputa partidária pelo governo federal e ascendiam à contraposição entre o planejamento participativo e democrático e o planejamento efetuado no âmbito do Estado central.

\section{CONFERÊNCIA NACIONAL DE EDUCAÇÃo E O PROJeto de LeI 8.035}

Dourado (2010), ao avaliar a implementação da Lei 10.172, de 9 de janeiro de 2001, que instituiu o PNE (20012011), considera que o PNE aprovado não se constituiu como base e diretriz para políticas, planejamento e gestão da educação nacional nem foi acionado como tal pelos diferentes segmentos da sociedade civil e política brasileira.

[...] o PNE foi secundarizado nos processos de gestão e decisão no âmbito do Executivo federal e não se corporificou em efetivos planos decenais de educação, nos âmbitos municipais e estaduais, como previsto na legislação. O cumprimento das metas e, sobretudo, as possíveis melhorias na qualidade da educação nacional efetivaram-se como resultantes de ações e políticas governamentais stricto sensu, sem ter o Plano como o epicentro do processo político (DOURADO, 2010, p. 686).
Aguiar (2010) conclui sua avaliação sobre o PNE (2001-2011) afirmando que ocorreram avanços no período em relação às metas e objetivos fixados no início, que o não cumprimento de outras não pode ser atribuído apenas à União e ressalta a necessidade de ações concertadas entre Estado e sociedade civil. Saviani (2010, p. 391), em documento orientador da I Conferência Nacional de Educação, caracterizou o Plano Nacional de Educação formulado no âmbito do executivo federal como uma proposta de reorganizar a educação na égide da redução de custos traduzida na busca da eficiência sem novos investimentos e que este se revelou um instrumento de introdução da racionalidade financeira na educação.

Esses artigos, embora publicados posteriormente, são expressivos do diagnóstico que orientou a realização da Conferência Nacional de Educação (CONAE), realizada em Brasília em 28 de março de $2010 .{ }^{6}$ Essa Conferência também tinha por objetivo indicar diretrizes e estratégias de ação para um novo Plano Nacional de Educação, previsto inicialmente para o período 2011-2020. Sob o tema "Construindo o Sistema Nacional Articulado de Educação: o Plano Nacional de Educação, Diretrizes e Estratégias de Ação", a CONAE foi precedida de conferências municipais e intermunicipais realizadas durante o ano de 2009, destinadas à discussão do documento-referência divulgado pelo Ministério da Educação.

A organização da CONAE foi de iniciativa do Ministério da Educação, em articulação com entidades da sociedade civil e movimentos sociais. Em entrevista concedida à revista Educação \& Sociedade, o coordenador-geral da Comissão Organizadora Nacional da CONAE, Francisco das Chagas Fernandes, secretárioadjunto do MEC, reporta aos eventos nacionais anteriores a ideia da realização da conferência; contudo, afirma, no caso da CONAE, que "[...] a grande reivindicação da sociedade era que o Estado estivesse presente na discussão da educação junto com os movimentos sociais" (ENTREVISTA, 2010, p. 1.033).

O Ministério da Educação foi um dos principais protagonistas da Conferência - a Comissão Organizadora do CONAE contou com a participação de representantes de todas as suas secretarias -, além de financiar as despesas necessárias a sua realização (ver a respeito: BRASIL, 2008, Portaria Ministerial 10, de 3 de setembro de 2008). Coube, também, ao Ministério a definição das competências da Comissão Organizadora da CONAE, o cronograma dos eventos preparatórios no âmbito dos estados, no Distrito Federal e nos municípios, participar da elaboração de documento-referência para subsidiar as discussões e do regimento interno que pautou o funcionamento da conferência. 
Quanto à participação das entidades não governamentais, Militão (2011, p. 8109) ressalta que a CONAE foi bem recebida pelos movimentos sociais, que esperavam maior aproximação com o governo de Luiz Inácio da Silva (2002-2010). Sob tal perspectiva, a Conferência teria possibilitado a aglutinação dos setores ligados à educação "marcados historicamente por divergências quanto às formulações das políticas educacionais". Para Santos (2010), a CONAE possibilitou maior aproximação entre gestores do Estado, acadêmicos, sindicatos e os diversos segmentos sociais do campo educativo.

A comissão organizadora da CONAE refletiu o protagonismo do MEC no planejamento e condução das políticas educacionais e a presença de novas orga- nizações, que emergiram no período, com objetivos de vocalizar demandas de reconhecimentos de diferenças e/ou diversidade, como, por exemplo, os Movimentos de Afirmação da Diversidade. Também agregou, no âmbito dos chamados Movimentos em Defesa da Educação, a entidade Todos pela Educação, mantida por grandes instituições financeiras e grupos empresariais, assim como contou com a participação da Confederação dos Empresários e do Sistema S7 (BRASIL, 2010, p. 4).

O ordenamento e a previsão do número de delegados e participantes da Conferência, com base nos critérios de escolha dos delegados fixados no Regimento Interno da CONAE, revelam a participação expressiva do Executivo Federal e de órgãos e entidades ligadas aos poderes públicos na Conferência (Quadro 4).

Quadro 4 - Previsão do número de delegados e participantes da CONAE

\begin{tabular}{|c|c|}
\hline Tipo de participação & Quantitativo previsto \\
\hline Delegados natos* & 71 \\
\hline Delegados eleitos nos estados - educação básica & 1.000 \\
\hline Delegados eleitos nos estados - educação profissional & 400 \\
\hline Delegados eleitos nos estados - ensino superior & 600 \\
\hline Total de delegados por segmentos - eleitos nos estados & 2.000 \\
\hline Delegados por setores - indicação nacional - ministérios da área social & 66 \\
\hline Delegados por setores - indicação nacional - órgãos colegiados normativos ou executivos & 57 \\
\hline Delegados por setores - indicação nacional - órgãos de fiscalização e controle & 6 \\
\hline Delegados por setores - indicação nacional - gestores do MEC & 83 \\
\hline Delegados por setores - indicação nacional - parlamentares & 54 \\
\hline Total de delegados por setores - indicação nacional & 266 \\
\hline Delegados por setores - indicação estadual - entidades municipalistas & 15 \\
\hline Delegados por setores - indicação estadual - instituições religiosas & 03 \\
\hline Delegados por setores - indicação estadual - movimento sindical & 54 \\
\hline Delegados por setores - indicação estadual - articulações sociais em defesa da educação & 120 \\
\hline Delegados por setores - indicação estadual - comunidade científica & 87 \\
\hline Delegados por setores - indicação estadual - instituições de empresários & 27 \\
\hline Delegados por setores - indicação estadual - movimentos de afirmação de diversidade & 104 \\
\hline Delegados por setores - indicação estadual - órgãos de fiscalização e controle & 58 \\
\hline Delegados por setores - indicação estadual - parlamentares & 79 \\
\hline Total de delegados por setores - indicação estadual & 547 \\
\hline Participantes-apoio (estrutura geral e feira de amostra) & 291 \\
\hline Participantes-imprensa & 44 \\
\hline Participantes - observadores - convidados - palestrantes & 281 \\
\hline Total geral & 3.500 \\
\hline
\end{tabular}

Fonte: Regimento Interno da CONAE -2010.

* Membros titulares e suplentes da Comissão Organizadora da Conferência Nacional da Educação. 
O Documento Final caracterizou a Conferência como "espaço social de discussão da educação brasileira, articulando os/as diferentes agentes institucionais, da sociedade civil e dos governos (federal, estaduais/DF e municipais), em prol da construção de um projeto e de um Sistema Nacional de Educação, como política de Estado". A mobilização social pela educação seria o objetivo maior da CONAE, uma "demanda histórica da sociedade civil organizada, especialmente das entidades representativas do setor educacional" (BRASIL, 2010, p. 12). A respeito da CONAE, afirma o diretor de políticas educacionais da União Nacional dos Estudantes (UNE):

Em 2010, a Conferência cumpriu o importante papel de retomar as articulações do movimento educacional a partir do PNE, para 2014 não vamos mais discutir o conteúdo do plano, mas sim como daremos um passo a mais na formulação de políticas e na estruturação do Sistema Nacional de Educação (UNE, 2013).

Se no período anterior foi a existência de proposições antagônicas de planejamento, o que orientou práticas discursivas no âmbito dos CONEDs, nesse segundo período a Conferência Nacional preparatória do II PNE tem o antagonismo subsumido mediante enunciados de participação conjunta entre Estado e sociedade na formulação do Plano Nacional de Educação.

\section{Planejamento educacional e a FORMAÇÃO DO CONSENTIMENTO ATIVO}

Os eventos analisados caracterizaram-se pela formulação de planos de educação de abrangência nacional. Convergem, ainda, ao adotarem procedimentos de consulta a atores não estatais com experiências diversas na área educacional, expressando dessa forma as mudanças conferidas ao planejamento educacional dominante no período ditatorial.

A Conferência de 1994 foi organizada e promovida no âmbito do Ministério da Educação com o apoio da UNESCO, da UNICEF, do CONSED e da UNDIME. A comissão organizadora era composta exclusivamente por membros do MEC e por um Grupo Técnico Especializado, constituído por professores-especialistas das universidades, por representante do INEP e do IPEA. A participação considerada nesse período centrava-se em pessoas e entidades consideradas como experts na área educacional. A novidade do período foi a participação da CNTE, ator que foi capaz de introduzir proposições diferenciadas das entidades governamentais e de especialistas em educação.

A sistemática de composição dos CONEDs se diferenciou dos demais eventos, pois esses foram organizados e apoiados majoritariamente por entidades de natureza sindical, ligadas à área da educação, por organizações de profissionais da educação (básica e superior) e pelas prefeituras municipais governadas pelo Partido dos Trabalhadores (PT). Esses congressos e a elaboração do PNE - Proposta da Sociedade Brasileira ocorreram sem a participação do governo federal e foram marcados pelas concepções dos atores sociais que se encontravam em oposição ao partido no governo.

A formulação do PNE - Projeto da Sociedade Brasileira - sustentou-se em construção e prática discursiva em contraposição à política educacional governamental. Esta, por sua vez, desconsiderou esses atores como interlocutores. A formação discursiva do período, que constituiu as articulações para o PNE, reiterava, em diferentes momentos e situações, a existência de projetos em oposição, reduzindo possibilidades de reconhecimento de aspectos comuns nas formulações de planejamento. Diagnósticos e objetivos convergentes ou mesmo comuns são reduzidos e, consequentemente, o modo como as proposições advindas dos CONEDs poderiam interagir com outras fontes e atores. O discurso, que legitimou os PNEs apresentado em 1998, dificultou o desenvolvimento de uma reflexividade capaz de compartilhar a constituição de ações e projetos por meio de processos interativos entre atores governamentais e não governamentais.

À participação de atores diversos no planejamento de mudanças das políticas públicas em educação é possível atribuir dois significados distintos e não necessariamente complementares. Por um lado, esses eventos contribuem para obter maior a disseminação de lógicas comuns de ação, permitindo a obtenção de consensos, ou seja, acordos no que diz respeito a objetivos, resultados e problemas existentes. Contribuem primordialmente para que atores responsáveis pela implementação em territórios socialmente os mais diversos persigam de forma ativa os resultados desejáveis. A produção do consentimento ativo requer práticas discursivas formadoras de valores e objetivos partilhados, orientadores das condutas, e especialmente requer a formação de subjetividades que compartilhem princípios identitários comuns.

Nesse sentido, a crítica formulada à fraca implementação do PNE (2001-2011) detectava os procedimentos do tipo top down, desde sua formulação e as bases sociais mais frágeis para a obtenção de maior participação, ou seja, de um consentimento ativo de seus implementadores.

A realização da CONAE em 2010 e os procedimentos em curso para a de 2012 demonstram a capacidade de articulação dos atores sociais posta em marcha pelos setores no governo brasileiro a partir de 2002. Sob a coordenação do governo federal, a disseminação dos objetivos previstos para o próximo Plano Nacional de 
Educação conta com a aprovação e a atuação de atores diversos, como a UNE, a CNTE, associações científicas da área educacional, entidades sindicais, o Movimento Todos pela Educação e o Sistema S. Esses atores, dentre outros, com capacidade de ação e vocalização de proposições diferenciadas, formularam objetivos e metas na Conferência Nacional para o Plano de Educação. Desse modo, paulatinamente o ato de planejar passou por mutações, de uma atividade de experts para a vocalização dos interesses e conflitos entre sujeitos desiguais. Nesse novo formato de planejamento, a constituição do consentimento ativo para além das diferenças requer práticas discursivas partilhadas.

\section{REFERÊNCIAS}

AGUIAR, Márcia Ângela da S. Avaliação do Plano Nacional de Educação 2001-2009: questões para reflexão. Educação \& Sociedade, v. 31, n. 112, p. 707-727, 2010.

BOLLMANN, Maria da Graça Nóbrega. Revendo o Plano Nacional de Educação: proposta da sociedade brasileira. Educação \& Sociedade, v. 31, n. 112, p. 657-676, 2010.

BORDIGNON, Genuíno. O planejamento educacional no Brasil. Brasília: MEC, Fórum Nacional de Educação, 2011.

BRASIL. Constituição (1988). Constituição da República Federativa do Brasil. Diário Oficial [da] República Federativa do Brasil, Brasília, 5 out. 1988.

BRASIL. Ministério da Educação e do Desporto. Plano Decenal de Educação para Todos. Brasília: MEC, 1993.

BRASIL. Ministério da Educação e do Desporto. Secretaria de Educação Fundamental. O que é o Plano Decenal de Educação para Todos. Brasília: MEC/SEF, 1993a

BRASIL. Ministério da Educação e do Desporto. Portaria n. 489 de 18 de março de 1993. In: Documenta, n. 387, p. 228, mar. $1993 \mathrm{~b}$.

BRASIL. Ministério da Educação e do Desporto. Conferência Nacional de Educação para Todos. Anais. Brasília, 1994.

BRASIL. Ministério da Educação e do Desporto. Pacto pela valorização do magistério e qualidade da educação: conferência nacional, acordo de educação para todos: compromisso com a qualidade e a profissionalização do magistério, por uma escola de cidadãos. República Federativa do Brasil, Ministério da Educação e do Desporto, Secretaria de Educação Fundamental, p. 16.1994a.

BRASIL. Lei n. 9.394, de 20 de dezembro de 1996. Estabelece as diretrizes e bases da educação nacional. Diário Oficial [da] República Federativa do Brasil, Brasília, 23 dez. 1996.

BRASIL. Lei n. 10.172, de 9 de janeiro de 2001. Aprova o Plano Nacional de Educação (PNE). Diário Oficial [da] República Federativa do Brasil, Brasília, 10 jan. 2001.

BRASIL. Ministério da Educação. Secretaria Executiva. Documento final da CONAE. Brasília: MEC/CONAE, 27 maio 2010.

BRASIL. Projeto de Lei n. 8.035, de 20 de dezembro de 2010. Aprova o Plano Nacional de Educação para o decênio 2011-
2020 e dá outras providências. Brasília, 20 dez. 2010. [Projeto de lei, encaminhado pelo Poder Executivo ao Congresso Nacional em 20 de dezembro de 2010].

COMITÊ EDITORIAL. Entrevista: A Conferência Nacional de Educação (CONAE) e o Plano Nacional de Educação (PNE). Educação \& Sociedade, Campinas, v. 31, n. 112, p. 1031-1058, jul.-set. 2010.

I CONED. Relatório com as diretrizes do I CONED para o Plano Nacional de Educação. Belo Horizonte, APUBH, 1997.

II CONED. Subsídios às discussões preparatórias do II CONED. Belo Horizonte, APUBH, 1997.

II CONED. Plano Nacional de Educação: proposta da sociedade brasileira. Belo Horizonte, APUBH, 1997a.

CUNHA, Célio da. Plano Decenal: fundamentos, trajetória e alcance social. Brasília, Em Aberto, ano 13, n. 59, jul.-set. 1993.

DOURADO, Luiz Fernandes. Avaliação do Plano Nacional de Educação 2001-2009: questões estruturais e conjunturais de uma política. Educação \& Sociedade, Campinas, v. 31, n. 112, p. 677-705, 2010.

EDITORIAL. Educação \& Sociedade, Campinas, v. 31, n. 112, p. 649-653, 2010.

ENTREVISTA de Francisco das Chagas Fernandes. Educação \& Sociedade, Campinas, v. 31, n. 112, p. 1031-1058, 2010.

FONSECA, Marília. O Banco Mundial como referência para a justiça social no terceiro mundo: evidências do caso brasileiro. Revista da Faculdade de Educação, São Paulo, USP, v. 24, n. 1, p. 37-69, jan.-jun. 1998.

FREITAG, Bárbara. "Educação para Todos" e a atuação da indústria cultural (mesa-redonda). Brasília, Rev. Bras. Est. Pedag., v. 67, n. 155, p. 171-206, jan.-abr. 1986.

FREITAS, Dirce Nei Teixeira de. Avaliação e gestão democrática na regulação da educação básica brasileira: uma relação a avaliar. Educação \& Sociedade, Campinas, v. 28, n. 99, p. 501-521, 2007.

GADOTTI, Moacir. Da palavra à ação. In: MEC/INEP. Educação para Todos: avaliação da década. Brasília, 2000.

GARCIA, Walter E. O Plano Decenal que nós queremos. Em Aberto, Brasília, ano 13, n. 59, jul.-set. 1993.

GOHN, Maria da Glória. Movimentos sociais e educação. 3. ed. São Paulo: Cortez (Questões da nossa época), 1999.

GUEDES, Edna G. S. O. Políticas públicas de formação de professores: PROCAP, os passos e descompassos de uma experiência de formação continuada no município de Buritizeiro (MG). 2003. Dissertação (Mestrado Educação) - Universidade de Uberaba, Uberaba, 2003.

HORTA, José Silvério Bahia. Plano Nacional de Educação: da tecnocracia à participação democrática. In: CURY, Carlos Roberto Jamil et al. (Org.). Medo à liberdade e compromisso democrático: LDB e Plano Nacional de Educação. São Paulo: Editora do Brasil, 1997.

MACHADO, Maria Aglaê de Medeiros. O plano decenal e os compromissos de Jomtien. In: MEC/INEP. Educação para Todos: avaliação da década. Brasília, 2000.

MAINGUENEAU, Dominique. Gênese dos Discursos. São Paulo: Parábola Editorial, 2008. 
MILITÃO, Silvio Cesar Nunes; PERBONI, Fábio; MILITÃO, Andreia Nunes. O novo PNE (2011-2020): convergências e divergências. CONGRESSO DE EDUCAÇÃO - EDUCERE, 10. Curitiba, 2011, p. 8103-8116. Anais. Disponível em: $<$ http:// educere.bruc.com.br/CD2011/pdf/5866 3463.pdf>. Acesso em: maio 2013.

SANTOS, Lucíola Licínio. Diretrizes curriculares nacionais para o ensino fundamental de 9 anos e o Plano Nacional de Educação: abrindo a discussão. Educação \& Sociedade, Campinas, v. 31, n. 112, p. 833-850, jul.-set. 2010.

SAVIANI, Demerval 2010. [Sistema de educação: Subsídios para a Conferência Nacional de Educação, 2010. Disponível em: <http://conae.mec.gov.br/images/stories/pdf/conae dermevalsaviani.pdf $>$. Acesso em: jan. 2013.

SILVA JÚNIOR, João dos Reis. Mudanças estruturais no capitalismo e a política educacional do Governo FHC: o caso do ensino médio. Educação \& Sociedade, Campinas, v. 23, n. 80, p. 201-233, 2002.

VALENTE, Ivan; ROMANO, Roberto. PNE: Plano Nacional de Educação ou carta de intenções? Educação \& Sociedade, Campinas, v. 23, n. 80, p. 96-107, set. 2002.

VIEIRA, Sofia Lerche. Estado e política de formação de magistério. Cadernos de Pesquisa, São Paulo, n. 103, p. 53-67, mar. 1998.

\section{Notas}

1 Após 1996, quando ocorreu o I CONED, foram realizadas outros quatro congressos: o II em 1997, também em Belo Horizonte, quando foi sistematizada uma proposta de Plano Nacional de Educação. O III na cidade de Porto Alegre em 1998, o IV em São Paulo em 2002 e o V em 2004 na cidade do Recife. Este artigo analisa os I e II CONEDs, que antecederam o envio ao Congresso Nacional do Projeto de Lei $5.155 / 1998$
$215 \%$ dos recursos vinculados à MDE dos estados e dos municípios foram destinados exclusivamente ao ensino fundamental, etapa obrigatória da educação básica. A CF/1988 e a LDBEN por sua vez estabeleceram, nesse mesmo período, que os municípios atuariam prioritariamente no ensino fundamental e na educação infantil e os estados subnacionais prioritariamente no ensino fundamental e médio.

3 No decorrer da tramitação legislativa no Congresso Nacional a esse projeto vai-se contrapor o substitutivo formulado pelo executivo federal (BRASIL, 1998a, Projeto de Lei 4173/1998).

4 Criada em 1990, a CNTE unificou várias Federações setoriais da educação numa mesma entidade nacional.

5 O FNDEP surgiu em 1986, em função das articulações para a elaboração da nova Constituição Federal pós-regime militar. Inicialmente denominado Fórum da Educação na Constituinte em Defesa da Escola Pública e Gratuita, seu lançamento oficial ocorreu em 9 de abril de 1987, na Campanha Nacional pela Escola Pública e Gratuita, na mesma semana da instalação da Subcomissão da Educação Cultura e Esporte da Constituinte, na primeira fase da Assembleia Nacional Constituinte. O fórum foi composto inicialmente por 15 entidades nacionais, a saber: ANDES - Associação Nacional de Docentes do Ensino Superior; ANPEd - Associação Nacional de Pesquisa e Pós-Graduação em Educação; ANDE - Associação Nacional de Educação; ANPAE - Associação Nacional de Profissionais de Administração da Educação; SBPC Sociedade Brasileira para o Progresso da Ciência; CPB - Confederação dos Professores do Brasil; CEDES - Centro de Estudos de Educação e Sociedade; CGT - Confederação Geral dos Trabalhadores; CUT Central Única dos Trabalhadores; FENOE - Federação dos Orientadores Educacionais; FASUBRA - Federação das Associações dos Servidores das Universidades Brasileiras; OAB - Ordem dos Advogados do Brasil; SEAF - Sociedade de Estudos e Atividades Filosóficas; UBES - União Brasileira de Estudantes Secundaristas; e UNE - União Nacional dos Estudantes (GOHN, 1999; BOLLMANN, 2010).

6 Dourado foi um dos elaboradores do documento-referência da CONAE, a partir do final de 2008, e Aguiar uma das responsáveis pela sistematização do relatório final da Conferência.

7 Os empresários brasileiros têm no Sistema S uma rede de escolas, laboratórios e centros tecnológicos espalhados pelo território nacional. O sistema é formado por organizações criadas pelos setores produtivos (indústria, comércio, agricultura, transportes e cooperativas) e parcela de seu financiamento provém de recursos públicos.

Artigo recebido em janeiro 2014

Aprovado em junho 2014. 